\title{
REFLETINDO A IMPORTÂNCIA DOS JOGOS LÚDICOS PARA O ENSINO DA MATEMÁTICA
}

\section{ARTIGO ORIGINAL}

SOARES, Fredson Rodrigues ${ }^{1}$

SALES, Elaine Cristina do Nascimento Sousa ${ }^{2}$

SOARES, Fredson Rodrigues. SALES, Elaine Cristina do Nascimento Sousa. Refletindo a importância dos jogos lúdicos para o ensino da matemática. Revista Científica Multidisciplinar Núcleo do Conhecimento. Ano 05, Ed. 08, Vol. 15, pp. $122-$ 129. Agosto de 2020. ISSN: 2448-0959, Link de acesso: https://www.nucleodoconhecimento.com.br/educacao/jogos-ludicos

\section{RESUMO}

Este trabalho tem como objetivo geral refletir acerca da importância dos jogos Matemáticos nos processos de ensino e aprendizagem da Matemática dos alunos do Ensino Fundamental séries finais. As atividades lúdicas favorecem a socialização entre os alunos, fazendo com que experimentem novas situações e manipulem materiais concretos. Entende-se que a ludicidade tem ganhado espaço nos planejamentos pedagógicos pois além de atingir os objetivos elencados ainda melhora a motivação do estudante que consegue perceber-se como autor do seu aprendizado. O pano de fundo desta pesquisa está em conformidade com as pesquisas de autores como Oliveira (2005), Piaget (1998), Kishimoto (2003), dentre outros nos quais

\footnotetext{
${ }^{1}$ Mestrado em Mestrado Em Ciências Da Educação. Especialização em Gestão E Coordenação Pedagógica. Especialização em Especialização No Ensino Da Matemática. Graduação em Física. Graduação em Licenciatura Em Pedagogia.

2 Especialização em Administração da Educação com Ênfase em Educação a Distância. Especialização em Especialização "Latu Sensu" em Biologia e Química. Graduação em Licenciatura Específica em Biologia.
} 
conversam entre si sobre a importância do lúdico e suas contribuições na contextualização de conteúdo, motivação e realização de aulas prazerosas, facilitando assim o processo de ensino e aprendizagem dos alunos nessa etapa da educação básica.

Palavras-Chave: Lúdico, aprendizagem, matemática, interação, motivação.

\section{INTRODUÇÃO}

O presente artigo mostra a importância da inserção do lúdico na prática educativa por ser uma atividade que altera as estruturas plásticas neurais de maneira prazerosa, contribuindo para o desenvolvimento dos estudantes em seus aspectos social, intelectual e cognitivo.

A utilização de jogos didáticos abre espaço para o estudante participar do processo de aprendizagem sem demonstrar os traumas de experiências passadas, visto que quando o assunto é matemático, muitos tabus e conceitos prévios de dificuldades surgem, tornando um impedimento na aprendizagem.

Reafirmando a importância que o ato de brincar tem frente aos processos ruptores da formação de novas conexões nervosas o que será interpretado como processo de aprendizagem, para que tal intento seja alcançado, as propostas pedagógicas devem estar em acordo com os currículos escolares por ser utilizada como ferramentas contribuinte a auxiliar o professor para o processo pedagógico.

Para Piaget (1998, p. 67), "o processo de ensino e aprendizagem tornou-se um campo de possibilidades, onde o educador deve proporcionar meios que estimulem a procura do conhecimento". Entende-se que para atingir esse objetivo, pode-se utilizar jogos didáticos como suporte metodológico que apoiem os processos de ensino e aprendizagem dos estudantes independentemente do nível escolar em que estejam.

O presente artigo apresentará caráter qualitativo, na qual traz a qualidade das informações colhidas que se refere a pesquisas qualitativas. Pádua (2004, p.36) 
afirma que: "[...] tem se preocupado com os significados dos fenômenos processos sociais, que permeiam a rede de relações sociais."

Para tanto, utilizará como procedimento técnicos para desenvolver este estudo a pesquisa bibliográfica através de livros e revistas da educação e com base nos teóricos com: Kishimoto (2002), Piaget (1997), Santos (2002), Vygotsky (2003), Oliveira (2005), na qual ressaltam-se a importância do papel do lúdico para o desenvolvimento e aprendizagem das crianças.

No âmbito social, esta pesquisa justifica-se por mostrar a relevância de conhecer o valor do lúdico no letramento matemático podendo ser utilizado como ferramenta pedagógica no qual facilitará no desempenho da aprendizagem dos estudantes.

\section{DESENVOLVIMENTO}

\section{O LÚDICO E O DESENVOLVIMENTO HUMANO}

De acordo com Piaget (1997) o desenvolvimento do ser humano, acontece de forma processual, por etapas e o todo ser humano passa por cada uma destas etapas. Sendo assim, ele aponta quatro estágios que de acordo com Bock (1999): O primeiro estágio: sensório moto (0 á 2 anos); segundo estágio: pré-operatório, (2 a 7 anos); terceiro estágio: operações concretas (7 a 12 anos) e quarto e último estágio: operações formais (11 a 12 anos).

Segundo Vygotsky (1984, p.134), "O brinquedo cria uma zona de desenvolvimento proximal na criança (...) com o brinquedo é como se ela fosse maior do que ela é na realidade". Com o uso de jogos para fins didáticos a criança aprende a agir numa esfera cognitiva, pois a criação de uma situação imaginária pode ser considerada como um meio para desenvolver o pensamento abstrato da criança.

É através dos jogos didáticos que a criança ou aluno formula conceitos, relaciona ideias, estabelece relações lógicas, desenvolve a expressão oral, corporal, reforça habilidades sociais, reduz a agressividade, integra-se na sociedade e constrói seu próprio conhecimento. O jogo é essencial para a saúde física, mental e simbólica 
permitindo vivências do mundo adulto, possibilitando a mediação do mundo real com o mundo imaginário, ou vice-versa, desenvolvendo habilidades e construindo conhecimentos de forma significativa.

A palavra lúdica tem sua origem latina "ludus" que significa "jogo" conforme o minidicionário Aurélio (2001). Desde a mais tenra idade o lúdico se faz presente na vida do ser humano e permanece até a atualidade como instrumento que auxilia no processo de aprendizagem para as crianças.

Desde a antiguidade durante a época Greco romana já tinha um papel importante e já se utiliza-se na prática educativa, pois os jogos e brincadeiras eram vistos como instrumentos facilitadores para o desenvolvimento, assim como, a aprendizagem das crianças. Dessa forma, as crianças tinham que ocupadas por jogos e brinquedos para que assim desenvolvessem a aprendizagem. Desse modo, Oliveira, (2005, p. 40): "demonstrando que o homem brinca e joga independentemente do seu tempo". Portanto, desde a antiguidade até a atualidade a atividade lúdica é de fundamental importância para o processo de aprendizagem do indivíduo.

Dessa forma, o papel assumido pelos alunos durante a interação com jogos, parte do conhecimento que eles têm das características do personagem no qual interpretam, da imitação de alguém, de alguma história, da televisão, de alguma experiência vivida, da imitação do professor, ou de determinado papel. O estudante pode recriar, relacionando diversas situações já vividas ou vivenciadas por ela na interação com as outras no cotidiano escolar.

É por meio do lúdico que a criança expressa à maneira como ela vê o mundo, reflete, ordena, desorganiza, destrói e constrói o mundo a sua maneira de pensar. É também um espaço onde ela pode expressar de modo simbólico, suas fantasias, seus desejos, medos, sentimentos agressivos e o conhecimento que vai construindo a partir das experiências que vivem, sendo assim uma atividade principal da criança. 


\section{- PAPEL DO LÚdICO NO PROCESSO DE ENSINO E APRENDIZAGEM}

Muito se discute sobre a importância dos jogos na educação, pois acredita-se que eles proporcionam a construção de valores para cada fase na vida dos educandos. Logo, tanto na infância onde a criança encontra-se na Educação Infantil ou na adolescência no Ensino Fundamental, os jogos possuem ou podem ser utilizados com objetivos pedagógicos. Muitos jovens apresentam resistência à escola e ao ensino de modo geral, acredita-se pelo fato de a mesma não despertar curiosidade, motivação e não Ihes proporcionar prazer, trabalhando de forma tradicional e mecânica os conteúdos da grade curricular.

Para Piaget (1988, p. 39): "O desenvolvimento da criança acontece através do lúdico. Ela precisa brincar para crescer, precisa do jogo como forma de equilíbrio com o mundo". Evidencia-se assim a grande importância dos jogos como ferramenta de ensino, pois fazem parte da vida da criança desde a infância devendo ser mediado pelo professor para proporcionar aprendizagem no decorrer de sua vida estudantil.

Os jogos possibilitam o estudo da relação do aluno com o mundo externo, integrando estudos específicos sobre a importância deles na formação da personalidade do ser humano. Através dos jogos, o aluno forma conceitos, seleciona ideias, estabelece relações lógicas, integra percepções, faz estimativas compatíveis com o crescimento físico, o que é mais importante, a socialização e interação em grupo. O trabalho com jogos tem valor educacional intrínseco e não apenas extrínseco, pois além desses valores que lhes são inerentes, tem sido utilizado como recurso pedagógico de forma ativa nos processos de ensino da Matemática.

Podemos elencar algumas razões para a utilização dos jogos nos processos de ensino e aprendizagem: as atividades lúdicas correspondem a um impulso natural da criança e neste sentido, satisfazem uma necessidade interior, pois o ser humano apresenta uma tendência lúdica. $O$ jogo apresenta dois elementos que o caracterizam: o prazer e o esforço espontâneo e as situações lúdicas mobilizam esquemas mentais. Sendo 
uma atividade física e mental, os jogos acionam e ativam funções psicológicas, neurológicas e mentais, estimulando e desenvolvendo o pensamento.

Dessa forma, o elemento que separa um jogo pedagógico do outro de caráter apenas lúdico é este, onde se desenvolve o jogo pedagógico com a intenção de provocar aprendizagem significativa, ou seja, aprendizagem em que o próprio aluno constrói da interação com o jogo, estimulando a construção de novo conhecimento e despertando interesse e o desenvolvimento de habilidades e competências.

Os jogos didáticos têm desempenhado importante papel no desenvolvimento dos alunos, na capacidade de imaginação iniciando na construção da própria identidade e da autonomia deles. Expressam a forma como um aluno reflete, ordena, desorganiza, destrói e constrói o mundo a sua maneira. Acredita-se ser através dos jogos que os alunos podem compreender o que vê e o que constrói a partir da interpretação de uma situação vivenciada relacionando com seu cotidiano.

De acordo com o pensamento de Vygotsky (2003): "em resumo, o brinquedo cria na criança uma nova forma de desejos. Ensina a desejar, relacionando seus desejos a um "eu" fictício, ao seu papel no jogo e suas regras", evidenciando-se assim a construção de regras indispensáveis para a vida em grupo e para as relações diárias.

Como ferramenta educativa, o lúdico é capaz de modificar a própria dinâmica do sujeito, renovando e permitindo construções diversas e importantes para a vida do indivíduo em sociedade. Embora esteja jogando, mais é nesse jogar onde o aluno poderá levar seu mundo a sério, fazendo descobertas incríveis, construindo conceitos, valores e aprendendo a interagir com o próximo, construindo assim qualidades que permitam e favoreçam a convivência em sociedade. 


\section{DESAFIOS DO ENSINO DA MATEMÁTICA E A UTILIZAÇÃO DO LÚDICO}

$\mathrm{O}$ ato de ensinar é carregado de gestos de atenção e de cuidado com o outro. Para os que aprendem, esse processo o inclui numa nova perspectiva seja ela educacional e até mesmo social.

Numa sociedade capitalista, o letramento matemático traz significados que vão além de resultados satisfatórios em avaliações, incluindo as personagens do processo de aprendizagem no caminho para o acesso ao patrimônio cultural do saber.

Historicamente, o primeiro obstáculo no ensino da matemática está no "não apreço a ela", ou seja, seu aparente distanciamento da realidade conduziu a uma visão distorcida da sua real conexão com as demais ciências, pois sendo ela também uma ciência, a matemática modela as outras que é por esta, remodelada.

Assim, os jogos lúdicos são concebidos atualmente como método pedagógico eficiente para a estruturação dos fundamentos matemáticos e do desenvolvimento dos estudantes, tornando-se uma metodologia ou ferramenta importante para a prática cotidiana dos alunos mediados pelo professor. Através dos mesmos o indivíduo apreende a agir em situações diversas, desenvolvendo habilidades necessárias para a solução de situações problemas do seu cotidiano. Assim, lecionar matemática é fortalecer o senso lógico, atiçar o pensamento autônomo, a imaginação e a técnica de resolver problemas, objetivo este que poderá ser alcançado com a utilização de jogos didáticos nos processos de ensino e aprendizagem.

O elo entre o ensino de matemática e o uso do lúdico está na alta probabilidade de desenvolver no estudante a autoconfiança em si próprio, motivando-os a superarem seus desafios através da desmistificação negativa sobre aprender matemática, sendo o jogo utilizado como instrumento de concentração, estímulo ao raciocínio lógico e desenvolvimento de estratégias, interpretar um problema matemático será como decifrar a pista de um jogo, o estudante pensa, interpreta, busca soluções, brinca e aprende. 


\section{CONSIDERAÇÕES FINAIS}

A busca por um ensino eficaz ao que a sociedade exige das instituições escolares, tem promovido uma onda de anseio entre os profissionais de educação por novas estratégias facilitadoras do ensino. Liada a essa realidade, é comum vermos a imagem negativa de ensinar e de aprender conteúdos matemáticos. Diversos são os motivos, dentre eles, a própria percepção do distanciamento do letramento matemático da realidade e das suas intrínsecas conexões com as demais áreas do conhecimento humano.

O desenvolvimento de estratégias metodológicas em que 0 ato de brincar esteja relacionado com a aprendizagem tem obtido resultados muito significativos quando se comparado ao ensino do mesmo conteúdo sem o uso de jogos lúdicos.

Independente da fase de desenvolvimento humano, interagir com o outro é inerente a nossa espécie e acontece nas mais simples atividades. Quando elevamos esse processo ao ato de brincar e aprender, as afinidades para se chegar a resposta do jogo facilita a aquisição de muitos conhecimentos.

Nesse processo, uma peça fundamental está na mediação que o professor fará a partir da seleção e desenvolvimento dos jogos de acordo com a etapa do desenvolvimento em que os estudantes se encontram, o currículo acadêmico e os níveis de proficiência que se espera que os estudantes alcancem.

Com base nos autores que serviram de embasamento teórico para a escrita deste trabalho, observou-se a concordância entre os mesmos no tocante à importância ou inserção das atividades lúdicas como suporte metodológico no processo de ensino e aprendizagem da matemática. Dessa forma, os jogos didáticos tornam-se uma excelente ferramenta metodológica que contribui para o processo de ensino, motivando para aprendizagem, despertando interesse dos alunos no seu processo de desenvolvimento pessoal, comprovando a teoria com a prática através do estudo com jogos. 
Todavia, é importante destacar que o professor precisa de formação continuada para que possa aprender a trabalhar de forma ativa e construtiva com jogos no ensino da Matemática, no sentido de garantir o desenvolvimento de habilidades essenciais para assimilação de conteúdos e elevação do rendimento escolar de seus alunos no tocante a aprendizagem da Matemática.

Tem-se então que a utilização de jogos nos processos de ensino e aprendizagem da matemática é uma metodologia de ensino que permite a produção de conhecimentos de forma prática, prazerosa, descontraída e divertida.

\section{REFERÊNCIAS}

AURÉLIO, B.T. de H. Mini Aurélio Escolar Século XXI. Nova fronteira. São Paulo, 2001.

BOCK, A, M.B. Psicologias: uma introdução ao estudo de Psicologia. São Paulo: Saraiva, 1999.

OLIVEIRA, G.G.M de. Brincando com sucata: a espontaneidade em jogo, 2005. Dissertação (Mestrado em psicologia) _ Universidade Estadual Paulista, Assis, 2005.

PÁDUA, E. M. M. de. Metodologia da Pesquisa: Abordagem teórico - prática. 10 ed. Campinas, SP. Papirus 2004.

PIAGET, J. Psicologia e Pedagogia. Rio de Janeiro: Forense Universitária, 1988.

A psicologia da criança. Ed. Rio de Janeiro, Bertrana Brasil, 1998.

VYGOTSKY,L. Pensamento e linguagem. Trad. M. Resende, Lisboa, Antídoto, 1979. A formação social da mente. Trad. José Cipolla Neto et alii. São Paulo, Livraria Martins Fontes, 1984. 
KISHIMOTO, T. M. Brinquedo e Brincadeira - usos e significações dentro de contextos culturais. In: SANTOS. Santa Marli Pires dos. Brinquedoteca: o lúdico em diferentes contextos. 7ª Edição. Petrópolis, RJ: Vozes, 2002.

Enviado: Agosto, 2020.

Aprovado: Agosto, 2020. 